\title{
An Erythropoietin Gene Polymorphism in the Hypoxia-Responsive Element at Position 3434 Is Possibly Associated with Hypertension
}

\author{
E.G.Schulz ${ }^{a}$ C.L. Neumann ${ }^{a} \quad$ J. Menne ${ }^{c} \quad$ V. Schettler ${ }^{a} \quad$ C. Mackenbrock ${ }^{a}$ \\ A.F. Popov ${ }^{f}$ G.C. Hagenah ${ }^{a} \quad$ J.Hinz ${ }^{b}$ M. Bargfeldt ${ }^{a}$ T. Gasser ${ }^{\text {e H. Haller }}$ \\ M. Hermann ${ }^{d}$ \\ ${ }^{a}$ Center of Nephrology Göttingen, Hypertension Care and Research Unit, and ${ }^{b}$ Department of Anaesthesiology, \\ Emergency and Intensive Care Medicine, University of Göttingen, Göttingen, and ${ }^{\mathrm{C} C l i n i c}$ for Nephrology, Hannover \\ Medical School, Hannover, Germany; ${ }^{\mathrm{d}}$ Department of Cardiology, University Hospital Zurich, and ${ }^{\text {}}$ Department of \\ Biostatistics, University of Zurich, Zurich, Switzerland; ${ }^{\mathrm{f}}$ Department of Cardiothoracic Transplantation and \\ Mechanical Support, Royal Brompton and Harefield Hospitals, London, UK
}

\section{Key Words}

Hypertension - Erythropoietin polymorphism - Genetics • End organ damage $\cdot$ Hypoxia-responsive element •

Ambulatory blood pressure monitoring

\begin{abstract}
Background/Aims: Several polymorphisms of vasoactive hormones have been implicated in hypertension. Erythropoietin (EPO) interacts with vasoactive substances, such as angiotensin II. Previously detected single nucleotide polymorphisms in the hypoxia-responsive element of EPO might be associated with hypertension and hypertensive end organ damages. Methods: 400 hypertensive patients and 200 age- and gender-matched normotensive controls were genotyped for an EPO polymorphism [cytosine (C)/thymine (T) single nucleotide polymorphism] at position 3434. Patients were grouped according to their genotype into the CC group (CC genotype) and the CT/TT group (CT and TT genotype). $\mathrm{BP}$ was measured by ambulatory BP monitoring. Results: The CC genotype was present in $87 \%$ of hypertensive pa-
\end{abstract}

\section{KARGER}

Fax +4161306 1234 E-Mail karger@karger.ch www.karger.com

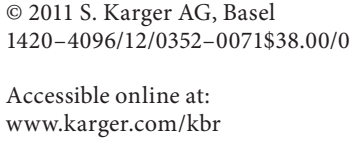

tients and in $78.5 \%$ of controls $(p=0.007)$. In addition, patients with the CC genotype had higher BP levels compared with CT/TT genotypes (BPsys $143.7 \pm 20.4$ vs. $136.1 \pm 13.5$ $\mathrm{mm} \mathrm{Hg}, \mathrm{p}=0.01$, and BPdias $85.8 \pm 11.6$ vs. $82.4 \pm 8.9, \mathrm{p}=$ 0.043 ) despite a nearly identical number of antihypertensive drugs $(2.3 \pm 1.5$ vs. $2.3 \pm 1.6 ; p=0.257) .100 \%$ of the small number of patients with end-stage renal disease $(n=15)$ had the CC genotype. Conclusion: The CC genotype of the EPO gene at position 3434 is more frequently found in patients with hypertension and is associated with higher BP levels.

Copyright $\odot 2011$ S. Karger AG, Basel

\section{Introduction}

Arterial hypertension is one of the most important preventable risk factors for the development of cardiovascular and renal disease $[1,2]$.

The etiology of primary hypertension is complex and has not been dissected completely. The interaction of exogenous factors such as obesity, sodium intake, nicotine, 
stress, socioeconomic conditions, and physical inactivity with vasoactive genes plays an important role in the pathophysiology of hypertension and development of hypertensive end organ disease [3].

Genome-wide screening and association analyses of single nucleotide polymorphisms (SNPs) detected several mutations and polymorphisms of vasoactive genes that are linked to hypertension and the development of hypertensive end organ damage [4].

Several studies demonstrated an interaction of erythropoietin (EPO) with vasoactive hormones [5] such as endothelin (ET) [6], nitric oxide (NO) [7], renin-angiotensin-aldosterone system [8] and prostaglandins. Indeed, EPO elicits vasoconstrictive, pro-aggregatory and proliferative effects, impairs endothelial function $[9,10]$, modulates ET-1-induced calcium mobilization and MAP-kinase activation in smooth muscle cells [11] and regulates the expression of ET-1 mRNA [12].

Transgenic EPO-overexpressing mice demonstrate an increased tubular expression of the prepro-ET-1 promotor sequence [13] and an activation of the tissue ET system [14]. On the other hand, these animals show increased endothelial NO synthase levels, NO-mediated endothelium-dependent relaxation and circulating and vascular tissue NO levels [7]. In addition, EPO enhances catecholamine sensibility of specific vessel receptors [5].

EPO is produced in the peritubular cells of the renal interstitium upon a decrease in oxygen saturation. Indeed, the inhibition of degradation leads to an accumulation of hypoxia-inducible factor-1 (HIF-1- $\alpha /-\beta)$ and increased binding to the hypoxia-responsive element (HRE), thus stimulating EPO gene expression $[15,16]$. HRE and HIF-1 are able to modulate the expression of several other genes during hypoxia, such as plasminogen activator inhibitor-1 or leptin $[17,18]$.

While several studies demonstrated the prognostic relevance of the hormone for acute vascular events such as stroke [19] and myocardial infarction [20,21], only one study showed a positive correlation between high normal hematocrit and hypertension in young males [22] while EPO-induced hypertension is widely recognized.

Four polymorphisms in the area of the HIF-1 and HNF4 binding sites were detected in patients with erythrocytosis [23]. However, exact regulatory mechanisms and functional relevance remain elusive. DNA methylation of cytidylyl-3'-5'-guanosine islands at the proximal promotor and the $3^{\prime}$ enhancer and the $5^{\prime}$-untranslated region impairs the EPO gene expression by blocking HIF-1-DNA binding [24]. Interestingly, the hypoxia-inducible ET-1 expression was also mediated by HIF-1-DNA binding [25]
Recently, the C3434T polymorphism in the $3^{\prime}$ HRE sequence of the $\mathrm{EPO}$ gene has been investigated in healthy, normotensive athletes [26]. However, this polymorphism had no influence on EPO levels in response to hypoxia. Thus, the aim of our study was to investigate the impact of the C3434T polymorphism at the HRE element on arterial hypertension, cardiovascular events and hypertensive end organ damage.

\section{Methods}

\section{Study Population}

The study was approved by the local institutional ethics committee of the Medical Faculty, University of Göttingen. After education and written informed consent, 400 Caucasian patients with essential hypertension and 200 normotensive Caucasian controls from a geographically defined area in lower Saxony were included, and detailed clinical data and medical history were assessed, blood samples were collected and DNA was extracted and frozen at $-80^{\circ} \mathrm{C}$. Baseline characteristics of all patients are shown in table 1 . Hypertensive patients were recruited in the hypertension outpatient clinic, and age- and sex-matched normotensive controls in the Department of Nephrology and Rheumatology of the Medical University of Göttingen. Patients with rheumatoid arthritis were excluded.

Hypertension was defined as 24-hour mean blood pressure $>130 / 80$ mm Hg (ABPM; Space Labs $90207^{\circledR}$ blood pressure monitor) or normotension under treatment with at least 1 antihypertensive drug, according to the recent hypertension guidelines. Hypertension was categorized and graded according to ABPM blood pressure levels and number of antihypertensive drugs because most of the patients were pretreated at the time of inclusion [27]. Hypertension grade 1 (HTN 1) means hypertensive without/ normotensive with 1 antihypertensive drugs ( $24 \mathrm{~h}$ mean $>130 / 80$ $\mathrm{mm} \mathrm{Hg} /<130 / 80 \mathrm{~mm} \mathrm{Hg}$ ABPM); 2 = hypertensive with $1 /$ normotensive with 2 antihypertensive drugs; 3 = hypertensive with 2 /normotensive with 3 antihypertensive drugs, and $4=$ hypertensive with 3 /normotensive with $\geq 3$ antihypertensive drugs.

Renal damage was categorized as $0=$ none; $1=$ proteinuria [clinical proteinuria was diagnosed if (a) the urine albumin excretion was $\geq 300 \mathrm{mg} /$ day or (b) the urine protein was $\geq 500 \mathrm{mg} /$ day] and/or elevated serum creatinine $(\geq 150 \mu \mathrm{mol} / \mathrm{l}) /$ decreased creatinine clearance (creatinine clearance, $15-89 \mathrm{ml} / \mathrm{min}$ per $1.73 \mathrm{~m}^{2}$ of body surface area); 2 = end-stage renal failure because of arterial hypertension (patients who required continuous renal replacement therapy)

Vascular atherosclerotic damage (VD) was categorized as $0=$ none, 1 = history of coronary artery disease (CAD) or occlusive artery disease or cerebrovascular affection, while vascular events were graded as absence $(=0)$ or presence $(=1)$ of stroke, myocardial infarction or amputation of extremities caused by hypoperfusion.

All HTN patients underwent echocardiography (Phillips Sonos $\left.5500^{\circledR}\right)$ and chronic heart failure $(\mathrm{CHF})$ was defined as $0=$ preserved systolic function, 1 = impaired systolic function (LVEF $<50 \%$ ), and left ventricular hypertrophy was graded as $0=$ none 
Table 1. Clinical data

\begin{tabular}{|c|c|c|c|c|c|c|c|c|c|}
\hline & \multicolumn{4}{|l|}{ HTN } & \multicolumn{4}{|l|}{ non-HTN } & \multirow{2}{*}{$\begin{array}{l}\text { p value } \\
\text { (HTN vs. } \\
\text { non-HTN) }\end{array}$} \\
\hline & $(\mathrm{n}=400)$ & $\begin{array}{l}\text { CC } \\
(n=348)\end{array}$ & $\begin{array}{l}\mathrm{CT}+\mathrm{TT} \\
(\mathrm{n}=52)\end{array}$ & $\begin{array}{l}\mathrm{p} \text { value } \\
(\mathrm{CC} \text { vs. } \\
\mathrm{CT}+\mathrm{TT})\end{array}$ & $(\mathrm{n}=200)$ & $\begin{array}{l}\text { CC } \\
(n=157)\end{array}$ & $\begin{array}{l}\mathrm{CT}+\mathrm{TT} \\
(\mathrm{n}=43)\end{array}$ & $\begin{array}{l}\mathrm{p} \text { value } \\
\text { (CC vs. } \\
\mathrm{CT}+\mathrm{TT})\end{array}$ & \\
\hline Age, years & $54.3 \pm 16.1$ & $54.4 \pm 15.7$ & $53.8 \pm 19.0$ & 0.81 & $54.1 \pm 16.2$ & $53.9 \pm 16.4$ & $55.0 \pm 15.3$ & 0.697 & 0.917 \\
\hline Male & $212(53)$ & $184(52.9)$ & $28(53.8)$ & 0.896 & $106(53)$ & $82(52.3)$ & $24(55.8)$ & 0.679 & 1 \\
\hline BMI & $26.9 \pm 4.4$ & $27.0 \pm 4.4$ & $26.3 \pm 4.1$ & 0.923 & $23.5 \pm 3.9$ & $23.6 \pm 3.7$ & $23.2 \pm 4.4$ & 0.637 & $<0.0001$ \\
\hline $\mathrm{SBP}, \mathrm{mm} \mathrm{Hg} / \mathrm{ABPM}$ & $142.7 \pm 19.8$ & $143.7 \pm 20.4$ & $136.1 \pm 13.5$ & 0.01 & $123.5 \pm 7.4$ & $123.6 \pm 7.4$ & $123.1 \pm 7.5$ & 0.699 & $<0.0001$ \\
\hline $\mathrm{DBP}, \mathrm{mm} \mathrm{Hg} / \mathrm{ABPM}$ & $85.3 \pm 11.3$ & $85.8 \pm 11.6$ & $82.4 \pm 8.9$ & 0.043 & $75.3 \pm 5.9$ & $75.4 \pm 5.8$ & $74.8 \pm 5.9$ & 0.532 & $<0.0001$ \\
\hline $\mathrm{DM}$ & $63(15.8)$ & $55(15.8)$ & $8(15.4)$ & 0.932 & $3(1.5)$ & $3(1.9)$ & 0 & 0.083 & $<0.0001$ \\
\hline HLP & $145(36.3)$ & $122(35.1)$ & $23(44.2)$ & 0.205 & $4(2)$ & $2(1.3)$ & $2(4.7)$ & 0.321 & $<0.0001$ \\
\hline Smoking & $82(20.5)$ & $70(20.1)$ & $12(23.1)$ & 0.622 & $39(19.5)$ & $32(20.4)$ & $7(16.3)$ & 0.533 & 0.08 \\
\hline AH drugs & $2.27 \pm 1.50$ & $2.26 \pm 1.48$ & $2.31 \pm 1.64$ & 0.257 & $0.05 \pm 0.3$ & $0.05 \pm 0.27$ & $0.02 \pm 0.2$ & 0.386 & $<0.0001$ \\
\hline $\mathrm{CCB}$ & $108(27.0)$ & $96(27.6)$ & $12(23.1)$ & 0.495 & 0 & 0 & 0 & & $<0.0001$ \\
\hline $\mathrm{BB}$ & $203(50.8)$ & $177(50.9)$ & $26(50)$ & 0.908 & $5(2.5)$ & $4(2.5)$ & $1(2.3)$ & 0.933 & $<0.0001$ \\
\hline ACEI/ARB & $215(53.8)$ & $187(53.7)$ & $28(53.8)$ & 0.988 & $1(0.5)$ & $1(0.06)$ & $0(0)$ & 0.319 & $<0.0001$ \\
\hline Diuretics & $161(40.3)$ & $134(38.5)$ & $27(51.9)$ & 0.066 & $3(1.5)$ & $3(1.9)$ & $0(0)$ & 0.083 & $<0.0001$ \\
\hline Statins & $55(13.8)$ & $49(14.1)$ & $6(9.6)$ & 0.620 & $2(1)$ & $1(0.06)$ & $1(2.3)$ & 0.487 & $<0.0001$ \\
\hline $\begin{array}{l}\text { Age at onset of } \\
\text { hypertension, years }\end{array}$ & $42.89 \pm 14.43$ & $42.75 \pm 13.94$ & $43.9 \pm 17.5$ & 0.6 & & & & & \\
\hline
\end{tabular}

$\mathrm{AH}=$ Antihypertensive drug; $\mathrm{HTN}=$ hypertensive patients; non-HTN = controls; $\mathrm{BMI}=$ body mass index; $\mathrm{SBP}=$ systolic blood pressure; $\mathrm{DBP}=\mathrm{di}-$ astolic blood pressure; ABPM = ambulatory blood pressure monitoring; HLP = hyperlipoproteinemia. Figures in parentheses indicate percentages .

or 1 = septum hypertrophy $(>11 \mathrm{~mm})$. Echocardiography was not performed in non-HTN patients.

The age at onset of hypertension was categorized as $0=18-38$ years, $1=39-59$ years, $2=>60$ years.

\section{Genotyping}

Genetic analysis was performed by persons blinded to clinical data. Whole blood was collected for DNA extraction from leukocytes by a standard method. For analysis of the C3434T SNP, the DNA fragment was amplified by polymerase chain reaction performed by the thermocycler GeneAmp ${ }^{\circledR} 2400$ PCR System Thermal Cycler (Perkin Elmer) according to previously described procedures (PCR; protocol: 35 cycles of $1 \mathrm{~min}$ at $94^{\circ} \mathrm{C}, 1 \mathrm{~min}$ at $58^{\circ} \mathrm{C}$ and $1 \mathrm{~min}$ at $72^{\circ} \mathrm{C}$; forward primer: $5^{\prime}$-GAA CTG AAA CCA CCA ATA TGA CTC-3'; reverse primer 5'-TTG GCA GCT GCC TTA CTG CGG TGA-3'; Invitrogen $\left.{ }^{\mathrm{TM}}\right)[23,28]$.

The determination of the genotype was performed by cyclesequencing with the ABI PRISM ${ }^{\circledR} 310$ Genetic Analyzer (Applied Biosystems) [29].

\section{Statistics}

Univariate analyses ( $\chi^{2}$ and t test) were used to compare the characteristics of the patient groups. Comparisons of different variables among the different genotypes were performed by $\chi^{2}$ analysis or ANOVA. Data were checked for normality before statistical analysis. Allele frequencies were estimated by counting, and Hardy-Weinberg's equilibrium was checked by $\chi^{2}$ test. Significance was considered at $\mathrm{p}<0.05$. All statistical analyses were computed by SPSS for Windows (SPSS Inc., Chicago, Ill., USA). For statistical investigation of the allele distribution, all patients were divided into 2 groups of genotypes (CC and CT + TT).

\section{Results}

\section{Baseline Characteristics}

Clinical data of the investigated population are shown in table 1.

There were no significant differences in age, gender, and smoking status between hypertensives and controls. As expected, systolic and diastolic blood pressure values were higher in hypertensives than in controls. Diabetes mellitus ( $\mathrm{p}<0.0001)$ and hypercholesterolemia $(\mathrm{p}<$ 0.0001 ) were more present in hypertensives, and BMI was higher compared to controls.

\section{Blood Pressure}

A different frequency of the $\mathrm{C}$ allele was observed. Indeed, the CC genotype was more frequently present in hypertensive patients $(87 \%, \mathrm{n}=348)$ than in non-hypertensive controls $(78.5 \%, \mathrm{n}=157 ; \mathrm{p}=0.007)$. CT/TT frequency was $13 \%(n=52)$ in hypertensive patients and $21.5 \%(\mathrm{n}=43)$ in controls.

In a second step, the different subgroups of hypertensive patients were examined (table 2). However, no association was detected for different grades of hypertension or age at onset of disease (table 3). The mean age at the onset of the disease in all patients was $42.9 \pm 14.4$. 
Table 2. EPO C3434T polymorphism genotypes of hypertensive patients and controls according to end-organ damage

\begin{tabular}{llclll}
\hline End organ damage & \multicolumn{1}{l}{ HTN } & & & \multicolumn{1}{c}{$\begin{array}{l}\text { non-HTN } \\
(\mathrm{n}=200)\end{array}$} \\
\cline { 2 - 5 } & $(\mathrm{n}=400)$ & $\begin{array}{l}\mathrm{CC} \\
(\mathrm{n}=348)\end{array}$ & $\begin{array}{l}\mathrm{CT}+\mathrm{TT} \\
(\mathrm{n}=52)\end{array}$ & $\begin{array}{l}\text { CC (TT + CT) } \\
\mathrm{p} \text { value }\end{array}$ \\
\hline Renal disease & $106(26.75)$ & $91(26.2)$ & $15(28.9)$ & 0.826 & $1(0.5)$ \\
Vascular disease & $114(28.5)$ & $100(28.7)$ & $14(26.9)$ & 0.758 & 0 \\
CAD & $94(23.5)$ & $84(24.1)$ & $10(19.2)$ & 0.659 & 0 \\
Left ventricular hypertrophy & $132(33)$ & $115(33.0)$ & $17(32.7)$ & 0.960 & not investigated \\
CHF & $36(9)$ & $33(9.5)$ & $3(5.8)$ & 0.383 & not investigated \\
Vascular events & $62(15.5)$ & $54(15.5)$ & $8(15.4)$ & 0.758 & $3(1.5)$ \\
\hline
\end{tabular}

Figures in parentheses indicate percentages.

Table 3. EPO genotypes of hypertension subgroups according to hypertension severity, stages of renal damage and age at onset of the disease

\begin{tabular}{llll}
\hline Subgroups & $\begin{array}{l}\mathrm{CC} \\
(\mathrm{n}=348)\end{array}$ & $\begin{array}{l}\mathrm{CT}+\mathrm{TT} \\
(\mathrm{n}=52)\end{array}$ & $\begin{array}{l}\mathrm{CC}(\mathrm{CT}+\mathrm{TT}) \\
\mathrm{p} \text { value }\end{array}$ \\
\hline
\end{tabular}

Hypertension grade

$\begin{array}{lrrr}\text { HTN } 1, \mathrm{n}=91(22.75) & 75(21.5) & 16(30.8) & 0.476 \\ \text { HTN 2, } \mathrm{n}=91(22.75) & 80(23.0) & 11(21.2) & \\ \text { HTN 3, } \mathrm{n}=81(20.25) & 73(21.0) & 8(15.4) & \\ \text { HTN 4, } \mathrm{n}=137(34.25) & 120(34.5) & 17(32.6) & \end{array}$

\section{Renal damage}

$\begin{array}{lrrr}\text { RD 0, } \mathrm{n}=294(73.5) & 257(73.8) & 37(71.2) & 0.196 \\ \text { RD } 1, \mathrm{n}=91(22.75) & 76(21.9) & 15(28.8) & \\ \text { RD 2, } \mathrm{n}=15(3.75) & 15(4.3) & 0(0) & \end{array}$

Age at onset of hypertension

$\mathrm{AOH} 1, \mathrm{n}=143(35.75) \quad 125(35.9) \quad 18(34.6) \quad 0.62$

$\mathrm{AOH} 2, \mathrm{n}=206(51.5) \quad 183(52.6) \quad 23(44.2)$

$\mathrm{AOH} 3, \mathrm{n}=51(12.75) \quad 40(11.5) \quad 11(21.2)$

Figures in parentheses indicate percentages.

However, hypertensive patients with the CC genotype had higher blood pressure levels compared to CT/TT patients, despite a comparable number of antihypertensive drugs (table 1).

\section{Renal Function}

No difference in renal function was observed between both groups (CC vs. CT/TT).

All patients with end-stage renal failure because of arterial hypertension $(\mathrm{n}=15)$ showed the CC genotype.

\section{Cardiovascular Disease}

The prevalence of CAD (CC: 24.1\%; CT/TT: 19.2\%) was comparable $(\mathrm{p}=0.488)$. Impaired left ventricular function was present in 33 (9.5\%) patients in the CC group compared to 3 patients $(5.8 \%)$ in the CT/TT group ( $\mathrm{p}=$ $0.06)$. Left ventricular hypertrophy was equally detected in both groups (CC: $33.0 \%$; CT/TT: $32.7 \%$; table 2).

Cardiovascular Events (Stroke, Myocardial Infarction, Amputation of Extremities) and Cardiovascular

Damage (CAD, Cerebrovascular Damage, Occlusive

Disease)

No difference was observed for cardiovascular events (CC: $15.5 \%$ and CT/TT: $15.4 \% ; \mathrm{p}=1.0$ ) or cardiovascular damage (CC: 28.7 and CT/TT: 26.9\%; $\mathrm{p}=0.87$; table 2).

\section{Homozygous TT Genotype}

The unique TT homozygous genotype was only seen in 1 patient (HTN III, 39 years old) with an early onset of hypertension and severe end organ damage including 2 -vessel CAD with previous myocardial infarction, impaired left ventricular function (EF 35\%), left ventricular hypertrophy, and impaired renal function.

\section{Discussion}

Over the last years, several polymorphisms in the HRE of the EPO gene have been identified. Although EPO plays an important role in the vascular homeostasis, all previously identified polymorphisms in the HRE have not been associated with essential hypertension, the course of disease, cardiovascular complications or hypertensive end organ damage especially in the renal vascular 
bed [23]. Therefore, we are the first to describe an association of an EPO/HRE C3434T polymorphism with arterial hypertension in a well characterized study population. Indeed, hypertensive patients show a higher prevalence of the CC genotype compared to matched normotensive controls. Furthermore, hypertensives subjects with the CC genotype have higher blood pressure levels than patients with the CT and TT genotype.

Despite the impact on blood pressure levels, the C3434T polymorphism might act differentially in different vascular beds. Indeed, all patients with ESRD in our cohort showed the CC genotype, while the only patient with the TT genotype had an early onset of severe hypertension with multiple end organ damage, including 2 -vessel CAD with previous myocardial infarction, impaired left ventricular function (LVEF 35\%), left ventricular hypertrophy and impaired renal function.

Interestingly, the analysis of associated cardiovascular diseases or cardiovascular damage revealed no impact of the polymorphism. The incidence of left ventricular hypertrophy, myocardial infarction, CHF or stroke was comparable in all groups and independent of the underlying genotype.

The functional relevance of the investigated polymorphism remains highly speculative. The $\mathrm{C} 3434 \mathrm{~T}$ polymorphism could be related to different gene expression and promotor activity as described by Wenger et al. [30]. Increased EPO levels can negatively affect vascular function by several mechanisms, such as inhibition of cyclooxygenase-dependent vasorelaxation [10], while decreased EPO levels could be associated with worse outcome after acute vascular events, such as stroke or myocardial infarction $[19,20]$.

The functional relevance of the described polymorphism should be investigated in specific cell culture con- ditions and in cardiovascular high-risk patients such as patients after acute myocardial infarction. With a closer look at our data, patients with CHF would be of specific interest. Indeed, although not significant, 9.5\% of all hypertensive patients with the CC genotype had an impaired systolic left ventricular function compared to only $5.8 \%$ of hypertensive patients with the CT/TT genotype. However, until now, no association of EPO polymorphism and CHF has been described.

Furthermore, the small hypertensive subgroup of patients with hypertensive end-stage renal failure should be separately investigated in a larger study.

A limitation of this study is the fact that data about functional changes of the EPO pathway are not available for the C3434T polymorphism. It is not known whether the CC genotype is associated with higher or lower EPO levels with increased or impaired activity of the EPO/ HRE. Unfortunately, EPO levels were not measured in our study. However, it is known that an SNP in the EPO promotor region significantly increased the transcriptional activity [31].

In conclusion, we demonstrated that the CC genotype at position 3434 of the HRE of the EPO gene is widely prevalent in the general population with an even higher prevalence in hypertensive patients. Furthermore, hypertensive patients with the CC genotype have higher blood pressure levels compared to hypertensive subjects with the CT/TT genotype.

\section{Acknowledgement}

The study was supported in part by grants of Novartis Pharma $\mathrm{GmbH}$, Germany.

\section{References}

1 Chobanian AV, Bakris GL, Black HR, Cushman WC, Green LA, Izzo JL Jr, et al: Seventh report of the Joint National Committee on Prevention, Detection, Evaluation, and Treatment of High Blood Pressure. Hypertension 2003;42:1206-1252.

-2 Mancia G. De Backer G, Dominiczak A, Cifkova R, Fagard R, Germano G, et al: Guidelines for the management of arterial hypertension: The Task Force for the Management of Arterial Hypertension of the European Society of Hypertension (ESH) and of the European Society of Cardiology (ESC). Eur Heart J 2007;28:1462-1536.
- 3 Imumorin IG, Dong Y, Zhu H, Poole JC, Harshfield GA, Treiber FA, et al: A gene-environment interaction model of stress-induced hypertension. Cardiovasc Toxicol 2005;5:109-132.

-4 Zhang K, Weder AB, Eskin E, O'Connor DT: Genome-wide case/control studies in hypertension: only the 'tip of the iceberg'. J Hypertens 2010;28:1115-1123.

5 Vaziri ND: Mechanism of erythropoietininduced hypertension. Am J Kidney Dis 1999;33:821-828.
-6 Miyashita K, Tojo A, Kimura K, Goto A, Omata M, Nishiyama K, et al: Blood pressure response to erythropoietin injection in hemodialysis and predialysis patients. Hypertens Res 2004;27:79-84.

7 Ruschitzka FT, Wenger RH, Stallmach T, Quaschning T, de Wit C, Wagner K, et al: Nitric oxide prevents cardiovascular disease and determines survival in polyglobulic mice overexpressing erythropoietin. Proc Natl Acad Sci USA 2000;97:11609-11613. 
8 Kuriyama S, Tomonari H, Tokudome G, Kaguchi Y, Hayashi $\mathrm{H}$, Kobayashi $\mathrm{H}$, et al: Association of angiotensinogen gene polymorphism with erythropoietin-induced hypertension: a preliminary report. Hypertens Res 2001;24:501-505.

$\checkmark 9$ Lariviere R, Lebel M: Endothelin-1 in chronic renal failure and hypertension. Can J Physiol Pharmacol 2003;81:607-621.

-10 Wada Y, Matsuoka H, Tamai O, Kohno K, Okuda S, Imaizumi T: Erythropoietin impairs endothelium-dependent vasorelaxation through cyclooxygenase-dependent mechanisms in humans. Am J Hypertens 1999;12:980-987.

-11 Kusano E, Akimoto T, Umino T, Yanagiba S, Inoue $\mathrm{M}$, Ito $\mathrm{C}$, et al: Modulation of endothelin-1-induced cytosolic free calcium mobilization and mitogen-activated protein kinase activation by erythropoietin in vascular smooth muscle cells. Kidney Blood Press Res 2001;24:192-200.

-12 Liefeldt L, Schmidt-Ott KM, Orzechowski HD, Distler A, Paul M: Transcriptional regulation of endothelin-1 by erythropoietin in endothelial cells. J Cardiovasc Pharmacol 1998;31(suppl 1):S464-S466.

-13 Slowinski T, Schulz N, Ruschitzka FT, Quaschning T, Bauer C, Theuring F, et al: Pattern of prepro-endothelin-1 expression revealed by reporter-gene activity in kidneys of erythropoietin-overexpressing mice. Clin Sci (Lond) 2002;103(suppl 48):44S-47S.

14 Quaschning T, Ruschitzka F, Stallmach T, Shaw S, Morawietz H, Goettsch W, et al: Erythropoietin-induced excessive erythrocytosis activates the tissue endothelin system in mice. FASEB J 2003;17:259-261.

15 Varma S, Cohen HJ: Co-transactivation of the $3^{\prime}$ erythropoietin hypoxia inducible enhancer by the HIF-1 protein. Blood Cells Mol Dis 1997;23:169-176.
16 Goldberg MA, Dunning SP, Bunn HF: Regulation of the erythropoietin gene: evidence that the oxygen sensor is a heme protein. Science 1988;242:1412-1415.

17 Gupta M, Mungai PT, Goldwasser E: A new transacting factor that modulates hypoxiainduced expression of the erythropoietin gene. Blood 2000;96:491-497.

18 Shibata T, Akiyama N, Noda M, Sasai K, Hiraoka $\mathrm{M}$ : Enhancement of gene expression under hypoxic conditions using fragments of the human vascular endothelial growth factor and the erythropoietin genes. Int $\mathrm{J} \mathrm{Ra}$ diat Oncol Biol Phys 1998;42:913-916.

19 Siren AL, Fratelli M, Brines M, Goemans C, Casagrande S, Lewczuk P, et al: Erythropoietin prevents neuronal apoptosis after cerebral ischemia and metabolic stress. Proc Nat Acad Sci USA 2001;98:4044-4049.

20 Parsa CJ, Kim J, Riel RU, Pascal LS, Thompson RB, Petrofski JA, et al: Cardioprotective effects of erythropoietin in the reperfused ischemic heart: a potential role for cardiac fibroblasts. J Biol Chem 2004;279:2065520662.

21 Camici GG, Stallmach T, Hermann M, Hassink R, Doevendans P, Grenacher B, et al: Constitutively overexpressed erythropoietin reduces infarct size in a mouse model of permanent coronary artery ligation. Methods Enzymol 2007;435:147-155.

22 Nishikido N, Kobayashi T, Kashiwazaki H Hematocrit correlates with blood pressure in young male office workers. Ind Health 1999 37:76-81.

23 Percy MJ, McMullin MF, Lappin TR: Sequence analysis of the $3^{\prime}$ hypoxia-responsive element of the human erythropoietin gene in patients with erythrocytosis. Biochem Mol Med 1997;62:132-134.
24 Wenger RH: Cellular adaptation to hypoxia: $\mathrm{O}_{2}$-sensing protein hydroxylases, hypoxiainducible transcription factors, and $\mathrm{O}_{2}$-regulated gene expression. FASEB J 2002;16: 1151-1162.

25 Camenisch G, Stroka DM, Gassmann M, Wenger RH: Attenuation of HIF-1 DNAbinding activity limits hypoxia-inducible endothelin-1 expression. Pflugers Arch 2001;443:240-249.

26 Jedlickova K, Stockton DW, Chen H, StrayGundersen J, Witkowski S, Ri-Li G, et al: Search for genetic determinants of individual variability of the erythropoietin response to high altitude. Blood Cells Mol Dis 2003;31: 175-182.

27 Bur A, Herkner H, Vlcek M, Woisetschlager C, Derhaschnig U, Hirschl MM: Classification of blood pressure levels by ambulatory blood pressure in hypertension. Hypertension 2002;40:817-822.

-28 Blanchard KL, Acquaviva AM, Galson DL, Bunn HF: Hypoxic induction of the human erythropoietin gene: cooperation between the promoter and enhancer, each of which contains steroid receptor response elements. Mol Cell Biol 1992;12:5373-5385.

-29 Smith LM, Sanders JZ, Kaiser RJ, Hughes P, Dodd C, Connell CR, et al: Fluorescence detection in automated DNA sequence analysis. Nature 1986;321:674-679.

30 Wenger RH, Rolfs A, Spielmann P, Zimmermann DR, Gassmann M: Mouse hypoxia-inducible factor-1alpha is encoded by two different mRNA isoforms: expression from a tissue-specific and a housekeeping-type promoter. Blood 1998;91:3471-3480.

-31 Tsuchiya T, Okada M, Ueda M, Yasukochi Y: Activation of the erythropoietin promoter by a point mutation from GATA to TATA in the -30 region. J Biochem 1997;121:193-196. 